\title{
Rare unilateral Wormian Bone on Coronal suture and multiple sutural bones on Lambdoid suture: a Case Report
}

\author{
Dr. Padmaja Vasi M.B.B.S., M.D. \\ (Assistant Professor in Anatomy, Gandhi Medical College, Secunderabad - 500 025, Andhra Pradesh, India)
}

\begin{abstract}
Wormian bones or Sutural bones are small bones found on sutures of the skull. They vary in size, shape and number. During the Osteology demonstration class for under graduate students in Gandhi Medical College, Secunderbad, it was found that a rare occurrence of wormian bone on Coronal suture and multiple Sutural bones were seen on the Lambdoid suture of an adult Indian skull. It is important to know about these sutural bones because they can mislead the diagnosis in fracture of the skull. Knowledge of these bones is important to Radiologists, Neuro Surgeons and Orthopedic Surgeons.
\end{abstract}

Keywords: Skull, wormian bone, Coronal suture, Lambdoid suture, Lambda, Inca bone.

\section{INTRODUCTION}

Wormian Bones (WB) are small irregular bones found in the vault of the skull. They are formed by additional ossification centers. They may occur in or near the sutures. They are most numerous in the labdoid suture. An independent bone at the lambda is called "Inca Bone" or "Goeth's Ossicle". Rarely they may be seen at pterion (epipteric bone), at Bregma (OS Kerckring). The sutural bones are small and bilateral. The Inca bone was common in the skull of Incas and is still present their Andean descendants [1]. They are named after Ole Worm (1588-1655), a Danish Physician. Usually not more than several are found in single individual but more than hundred have been found in hydrocephalic adult skull [2]. Wormian bones are the markers for various diseases and are important in the primary diagnosis of brittle bone disease, osteogenisis imperfecta [4].

Wormian bones may also be seen in: Pycnodysostosis, Osteogenesis imperfecta, Rickets, "Kinkyhair" Menke's syndrome, Cleidocranial dysostosis, Hypoparathyroidism and hypophosphatasia, Otopalatodigital syndrome, Primary acro-osteolysis, Down's syndrome. These causes can be remembered by the mnemonic "PORKCHOPS" [5].

\section{CASE REPORT}

During the routine Osteology demonstration class for under graduates, we found a rare wormian bone which is unilateral and is present on the left side of coronal suture. Its shape is in the form of a flower as shown in fig. 1. In another skull, we have noticed three wormian bones - two are present on either side of the lambda which are also known as Inca bones and another sutural bone is present adjacent to the lambda on the left side of the lambdoid suture appearing larger in size when compared to the Inca bones as shown in fig. $2 \& 3$.

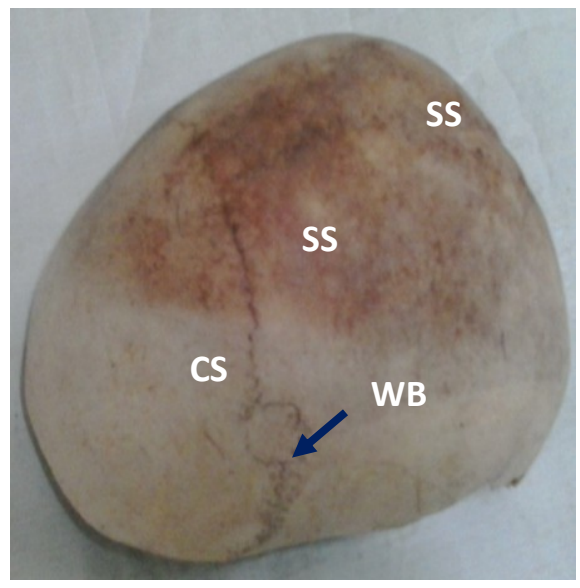

Fig. 1: Rare unilateral wormian bone on left side of the coronal suture

CS: Coronal Suture, SS: Sagittal Suture, WB: Wormian Bone
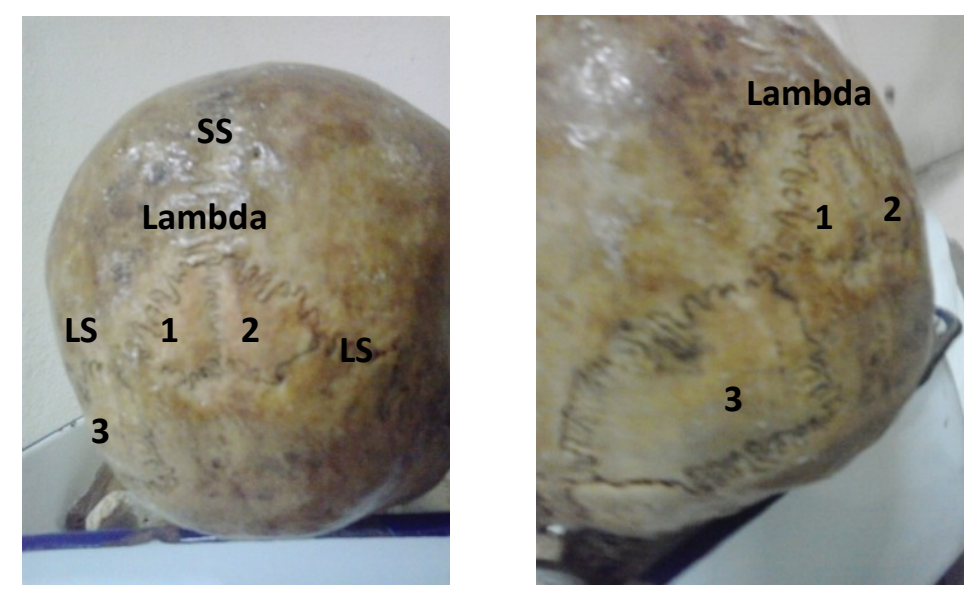

Fig. 2\&3: Multiple Wormian bones on Lambdoid Suture LS: Lambdoid Suture, SS: Sagittal Suture,

1, 2, 3: Wormian Bones 


\section{DISCUSSION}

Sutural bones (Wormian Bones) are very common in skull according to Bregman et.al. nearly $40 \%$ of skulls contain sutural bone in the vicinity of Labdoid suture. Next common sutural bone is the epipteric bone (Pterion Ossicle) found near the former and antero fontanellae [6]. Wormian bones are found in both sexes in similar percentages as well as in both sides of the skull, being predominantly symmetrical (Hanihara and Ishida 2001: 10). They can have different irregular shapes (round, oval, oblong, triangular, quadrilateral and polygonal have all been reported) and can vary from under $1 \mathrm{~mm}$ in diameter to $5 \times 9 \mathrm{~cm}$ or $1-2$ inches in diameter.

Wormian bones articulate with the surrounding bones by sutures with indentations more complex on the outer surface of the skull than on the inner aspect. (Parker 1905:12; Sanchez Lara et al. 2007:1) [7]. Earlier studies have shown that the presence of sutural bones is associated with other cranial and central nervous system abnormalities [8\&9]. Occurrence of the wormian bones is controlled by the genetic factor [10]. Although they are most commonly found in the posterior sutures (lamboidal and occipito-mastoid sutures), they can occur in any cranial suture and fontanels. They can develop either from independent ossification centres or by their separation from primary centres (Chambellan 1882 in Parker 1905, Sanchez Lara et al. 2007) [11].

The present case report reveals that the wormian bones are unilateral in occurrence on the left side of the Coronal suture which is a rare condition. It also presents the case of multiple wormian bones along Lambdoid Suture instead of single inca bone, two inca bones were seen on either side of the Lambda.

\section{CONCLUSION}

Anatomical knowledge of wormian bones is clinically important because the series of the wormian bones like the present case may lead to problems in the posterior approach of the cranial cavity. These bones may mislead the diagnosis when X-rays are taken and they may be mistaken for fractures.

\section{REFERENCES}

[1] Vishram Singh, Anatomy of Head, Neck \& Brain 2009 Reed Elsevier India Pvt Limited, New Delhi.

[2] Hussain Saheb S et al / J Biomed Sci and Res., Vol 2 (2), 2010,116-118

[3] Dr. Akram Abood Jaffar. "Sutural bones". Archived from the original on 2009-10-25.

[4] Glorieux FH, Osteogenesis Imperfecta, Best Practice \& Research Clinical Rheumatology. 22:1, pp. 85-100. 2008

[5] Wormian Bones: Differential Diagnosis \#6, The Radiology Blog, Published April 27, 2012

[6] Bergman RA, Afifi AK, Miyauchi R. Skeletal systems: Cranium. In: Compendium of human anatomical variations. Baltimore, Urban and Schwarzenberg. 1988; 197-205

[7] Charles A, Parker M.D. Wormian bones. Robert press: Chicago. 1905;pp 5-6.

[8] Pryles CV, Khan AJ. Wormian bones. A marker of CNS abnormality? Am. J. Dis. Child. 1979; 133:380-382.

[9] Das S, Suri R, Kapur V. Anatomical observations on os inca and associated cranial deformities. Folia Morphol. (Warsz). 2005; 64: 118-121.

[10] El-Najjar M, Dawson GL. The effect of artificial cranial deformation on the incidence of Wormian bones in the lambdoidal suture. Am. J. Phys. Anthropol. 1977; 46: 155-160.

[11] Sanchez-Lara, P. A., Graham, J. M., Hing, A. V., Lee, J., \& Cunningham, M. (2007). The morphogenesis of wormian bones: A study of craniosynostosis and purposeful cranial deformation. American Journal of Medical Genetics Part A, 143 A(24), 3243-3251. 